\title{
Exploring student awareness on critical factors which shape community engagement in the health science disciplines at a South African higher education institution
}

\author{
Angeni Bheekie ( $\nabla$ abheekie@uwc.ac.za ) \\ University of the Western Cape https://orcid.org/0000-0003-0943-1280 \\ Mea van Huyssteen \\ University of the Western Cape \\ Hester Julie \\ University of the Western Cape
}

\section{Research article}

Keywords: Community engagement, dentistry, final year students, health science, nursing, occupational therapy, pharmacy, physiotherapy

Posted Date: August 20th, 2019

DOI: https://doi.org/10.21203/rs.2.13209/v1

License: (c) (1) This work is licensed under a Creative Commons Attribution 4.0 International License.

Read Full License 


\section{Abstract}

Background Community Engagement (CE) is cornerstone to South Africa's higher education transformative agenda. Teaching disciplines across faculties have adopted varied CE implementation strategies, due to different theoretical interpretations. Undergraduate health science students are traditionally exposed to CE experiential learning programs, preparing them for professional practice. This study investigated final year students' awareness of the critical factors which shape CE in the health science disciplines at a South African university.

Method An exploratory descriptive qualitative study was conducted at an engaged university located in the Western Cape. Five discipline- specific focus group discussions were conducted with twenty seven final year students, purposively selected from five health sciences faculties, using an adaption of Furco's self-assessment rubric. Thematic analysis was conducted on the transcribed data to identify the factors deemed critical for CE using Furco's self-assessment tool as the coding framework. Trustworthiness of the data and findings were ensured. Ethics approval was obtained indicating that the research satisfied the ethics principles related to informed consent, respect for the participants 'rights in terms of privacy, autonomy, beneficence and confidentiality.

Results The a priori themes identified were the university's philosophy and mission related to $\mathrm{CE}$, student involvement, faculty involvement, community participation and partnerships and institutional support for $\mathrm{CE}$. The cross-cutting themes that emerged across these critical factors of Furco' included: siloism in the university, interprofessional education and monitoring and evaluation for impact. These health science students indicated that CE awareness was limited to discipline-based programs, indicative of a siloed approach. In addition, varied theoretical interpretations of CE emerged. Interprofessional education was lacking across the disciplines, even though it underpins professional practice. Participants reiterated that a central CE unit is required to co-ordinate and evaluate CE programs. Occupational therapy participants, however, reflected a critical consciousness that is congruent with an assets-based approach to CE.

Conclusion The University of the Western Cape should facilitate stewardship in implementing Boyer's 'scholarship of engagement' to ensure consistency in CE approach in the health science curriculum. Such an approach would deepen students understanding and application of CE.

\section{Introduction}

Globally health professional education institutions are required to align their educational programs to enable graduates to be fit for purpose [1]. In essence health education institutions are required to be accountable to communities in which they serve. The World Health Organisation defines social accountability of health education institutions as 'the obligation to direct education, research and service activities towards addressing priority health concerns of the community, region and/or nation that they have a mandate to serve [2]. 
Health professional schools are required to re-orientate their educational programs to ensure that learning is contextualised, where primary concerns are addressed to improve the community's health and strengthen the health system [3]. Interprofessional education and team-based learning forms the bedrock for transformative learning where graduates aspire to become change agents to transform silos which exist between the health system and higher education institutions [3].

Social accountability is dependent on multi-stakeholder engagement to co-ordinate and integrate learning activities for a systems-based approach between the health education institution and the health system [4]. From the health education institutions perspective, both faculty and students are required to be in sync with learning objectives and activities to optimise the educational institution's mandate, and thus programme effectiveness. Monitoring and evaluation of educational programs would enable academic planners to determine if the health education institution's alignment with social accountability values of quality, equity, effectiveness and relevance [4].

Following South Africa's historical racial segregation, a key policy imperative, the White Paper on the Transformation of Higher Education (1997) stipulated that South African higher education institutions address injustices, by re-designing curricula aimed at social transformation [5]. Community engagement was embedded as a third pillar in higher education institutions along with teaching and research. Experiential learning programs such as service learning, was subsequently introduced among faculties.

Service-learning requires students to examine the relevance of real-life situations, placing them in challenging positions, which may allow them to reflect on factors which influence their response to such impediments [6]. In service-learning, diverse contexts and emotions are associated with student experiences, making it difficult to support a viable CE framework [6].Varied terminology which is synonymous with $\mathrm{CE}$ approaches such as volunteerism and work-integrated programs provide students with co-curricular service opportunities which are related, but not fully integrated, with their formal academic studies $[7,8]$. In the health sciences context, clinical training emphasizes observing and improving slowly harnessed skills throughout the curriculum, but unlike work-integrated learning, it does not always include opportunities for reflections [9]. Thus, reflection is a critical component of CE and facilitates the students' connection between the experience and the learning [10].

Various models and understanding of CE used as methods of engagement by higher education staff and students [11] could be reflective of current key differences noted in practices among graduates inside the workforce. While some academic units might have adopted a theoretical model for CE programs [12], the question that arises is whether health science students from the same campus are aware of the components of such a model and what meaning might they derive from it.

The Higher Education Quality Committee (2006) devised a good practice guide and a self-evaluation instrument to gauge the quality of service -learning at institutional, faculty, programme and module levels [13]. Most recently, the Academy of Science of South Africa (2018) published the consensus study report which underpinned the World Health Organisation's social accountability values [2], espousing competencies for inter-professional education and collaborative practice directed at primary health care 
level [14]. As the National Health Insurance emerges from the pilot phase, the agenda of finding a harmonious CE structure within the health science disciplines is crucial to sustain national and provincial healthcare goals [15].

The involvement of students in the development of relevant CE programs is pivotal in dismantling the current Eurocentric framework within higher education, while reinforcing indigenous knowledge and diversity through self-reflection and practice of CE [16]. The Fees Must Fall campaign (2014 - 2016) underpinned the power of student participation and activism aimed at addressing social inequity $[16,17]$. Early exposure to CE allows students to forge relationships between stakeholders and develop competency as healthcare professionals, serving as a viable resource for basic service delivery in high pressured public health facilities as they further engage health practitioners on the relevance of curricula $[18,19]$.While much has been documented about South African medical schools [20] embarking on reorientating curricula to address inequity and priority health concerns, the allied health science faculties have remained on the periphery. Some health science faculties in South Africa are not linked to medical schools, gauging final year student awareness of CE programs from across various health disciplines could be a start towards reshaping CE curricula within South African higher education institutions.

A structured self-evaluation tool could be used to gauge student perspectives about the discipline's CE programme with regard to the philosophy and mission, student involvement, faculty involvement, community participation and partnerships and institutional support mechanisms [21]. Such evidence could be used to improve existing institutional structures to coordinate efforts that are directed at strengthening alignment towards social accountability.

South Africa's health and education sectors are required to explore alternative ways to prepare and utilize the health workforce in order to address the health needs of its increasing population [22]. Thus, the academic institution is in a pivotal position to address communities' priority health needs with students by programs which produce graduates which are fit for this purpose [1].

This qualitative study aimed to gauge final year student awareness about CE in five health disciplines at the University of the Western Cape, which is not linked to a medical school. This health sciences study is linked to an arm of a national Engaged Teaching and Learning project, advocating for the conceptualization of CE as a core function throughout all course curricula within South African higher education institutions [23].

\section{Methodology}

\section{Study Design}

An exploratory descriptive qualitative design was used to explore student awareness of the critical factors which shape community engagement in their respective health science disciplines [24] utilizing focus group discussions [25]. 


\section{Research setting}

The University of the Western Cape (UWC) is one of four public universities located in the Western Cape, South Africa. During South Africa's apartheid era, the University was reserved primarily for the mixed population group classified as 'Coloured', resulting from co-habitation between black and white people. The University fought vehemently against apartheid and oppression, and strongly aligned itself with community outreach programs to address issues of social injustice [26]. In its' recognition as an 'engaged university', the institution offers undergraduate and post postgraduate programs in seven faculties. In 2017, of the total student enrolment (22 443), undergraduate student enrolment was recorded at 17595 and postgraduate at $4848 ; 25 \%$ of students were enrolled in the Faculty of Economic and Management Sciences, $18 \%$ in Arts, $16 \%$ in Science and $15 \%$ in Community and Health Sciences [27].

A strategic document states that the UWC is concerned with 'national transformation and social justice' imperatives and that students will be given the opportunity to 'engage in meaningful practical community service' with various stakeholders in order to become 'excellent professionals and citizens' [28]. Five health disciplines that include $\mathrm{CE}$ as an integral component of the undergraduate clinical programme were selected from three of the seven faculties [29]: Dentistry [Faculty of Dentistry], Nursing, Occupational therapy, Physiotherapy [Faculty of Community and Health Sciences] and Pharmacy [Faculty of Natural Sciences].

\section{Data collection}

The target population included final year undergraduate students who were enrolled in one of five selected health disciplines in 2018. The recruitment process entailed sending electronically the information sheet outlining the details of the research project to the CE coordinator of each discipline. The CE coordinators identified the class representatives with whom the trained data collectors had approached to assist with the recruitment of participants and to finalise the logistics for the five discipline-specific focus group discussions (FGD). Data collection proceeded after informed consent had been obtained from a purposive sample of final year students. The self-developed interview guide consisted of open-ended questions related to CE based on the different dimensions of the Furco tool [21].

\section{Data Analysis}

The audiotapes were transcribed verbatim. Transcriptions were coded, verified and themes were identified using the tool Furco as framework for the initial analysis [21]. In the transcript, each participant's verbatim response was coded with an alphabet to denote the health discipline, followed by a corresponding number that was assigned to each participant in the FGD. For example participant 1 within each health discipline was coded as follows: Pharmacy (P1), Nursing (N1), Dentistry (D1), Occupational therapy 
(OT1) and Physiotherapy (PT1). The quotes mentioned reflect responses obtained from the respective participants.

The following strategies of trustworthiness were employed to ensure that the findings were credible, confirmable, transferable and dependable [24]. The same interview guide was used for all FGD, a thick description is provided of the research setting, an audit trail was kept, member checking of transcriptions was done and an independent coder was employed.

\section{Results}

A total of five FGDs lasting approximately 55 minutes were conducted between April 2018 and May 2018. A total of 27 final year (fourth-year) undergraduate students participated in the study: Pharmacy $(n=4)$, Nursing $(n=5)$, Dentistry $(n=8)$, Occupational therapy $(n=5)$ and Physiotherapy $(n=5)$.

Primary themes and the sub-themes are summarised in Table 1. Cross-cutting themes that emerged continuously regardless of the section of the interview included: siloism in the university, interprofessional education and monitoring and evaluation for impact.

\section{The university's philosophy and mission of community engagement}

All participants defined community engagement in terms of direct interaction with people in underserved contexts. These interactions were described in terms of reaching out to communities to enrich their lives by identifying their needs, providing advocacy and offering support. The definition of community engagement differed across disciplines as their activities were determined by discipline curricula, which was particularly evident in Dentistry, Nursing and Pharmacy participants who mentioned that applying theoretical knowledge and skills, pertaining to a specific profession, in a practical setting was also a form of CE.

Three disciplines (Occupational therapy, Pharmacy, Physiotherapy) elaborated on different groups of people such as community members, representatives, peers and other healthcare workers who work collaboratively to reach a common goal which is usually to benefit the patient, or, to improve awareness of social injustice such as "gender-based violence" (N1) and "occupational injustices" (OT2).

"So, the community is the people you engage with, whether it's your peers, patients or other healthcare workers" (P3).

Occupational Therapy and Physiotherapy participants expressed a strong belief relating to implementation of projects, based on the needs of the community, where existing resources from the community were used to achieve a self-sustainable outcome in the practice of CE. Occupational therapy 
participants emphasized that accountability in addressing health related and social issues in the community were a major ethic behind the definition and practice of $\mathrm{CE}$.

"What we do when we go into a community's very doorstep is to look at what we call occupational injustices. That for us is where our discipline becomes unique because of what that term covers. We look at anything ranging from chronic diseases in the community to gangsterism in the community, to any sort of broad topic that fits occupational engagement of the community" (OT2).

Synonyms for CE where primarily discipline and task specific. These words included "Awareness programs" (D \& P); “Outreach programs" (D, N, P); “Community involvement” (N); “Education” (D); "Occupational potential, occupational consciousness, occupational engagement, occupational choice, occupational injustices” (OT); “Community integration and community reintegration” (PT).

The three CE terms that participants were asked to specifically define included service-learning, workintegrated learning and volunteerism. Participants were most familiar with service learning (in contrast to work integrated learning), which was embedded into the formal curriculum. Volunteerism was associated with co-curricular activities and its prominence was negated when compared to the importance of 'marks' and graduating.

Pharmacy, Dentistry and Nursing participants defined service-learning as undergraduates offering services to communities for free by applying their theoretical knowledge in a practical environment. Pharmacy and Physiotherapy participants agreed that during service-learning, students gain more knowledge from the community which they serve-through "hands on" (PT5) learning. The Occupational therapy participants defined service-learning by contextualizing theory to practical experiences which were supported by additional literature, assignments and research.

The five groups had different interpretations of work-integrated learning, which converged in the workplace. Pharmacy and Dentistry participants defined work-integrated learning as knowledge which is gained in the workplace after students have graduated. Nursing participants equated work-integrated learning with service-learning. Physiotherapy participants referred to work-integrated learning as professionals working together towards a common goal as well as having the ability to apply critical skills in the field by "thinking on your feet" (OT2).

Volunteerism was the least practiced among the participants, because it was associated with personal or co-curricular activities. Pharmacy, Nursing, Dentistry and Occupational Therapy participants collectively indicated that there were no volunteerism programs within their curricula. However, some participants revealed scenarios where some students have taken their own initiative to volunteer outside of their discipline. In contrast, Physiotherapy participants mentioned that volunteerism was an extended part of their curriculum which allowed students to lend their time at sports events, outreach programs and fundraising. 
"We have a sports function like the Cape Town Cycle Tour, they ask for students to volunteer at the massage stations, as well as the Two Oceans Marathon. And as a class, we started an outreach at one of the Church Highs disability homes" (PT3).

None of the participants had any knowledge regarding the vision ad mission of UWC and how CE was incorporated. Participants noted that this information might have been included in some of the UWC emails that they chose not to read.

Respondents from three disciplines (Dentistry, Nursing and Physiotherapy) mentioned that they were quite isolated from campus UWC so that they don't know much about CE activities across disciplines at the university.

\section{Student involvement in CE}

Participants associated preparation for CE in their disciplines with the service learning, community projects, clinical placements and outreach activities emanating from their formal curriculum, which would automatically include all students in CE activities. Participants could not really comment on CE preparation outside of their disciplines/curriculum except for their experiences in the interprofessional courses and activities presented by the Interprofessional Education (IPE) unit on campus. However, participants also noted that these activities were limited to health science disciplines, despite them being able to extrapolate the social injustices observed in communities to issues pertaining to non-health disciplines such as education and law.

Most groups did not speak much about leadership and advocacy in terms of CE. Dentistry and Occupational therapy participants believed their curricula provided ample opportunities for CE and advocating for community needs, thereby fulfilling an academic requirement for their discipline. Physiotherapy participants believed it was the responsibility of the students to undertake a CE initiative to address issues of inequity.

While participants noted that their marks and subsequently graduating was of prime importance, a feeling of self-satisfaction was identified as the 'reward and incentive' which prompted students to participate in CE.

"No [there are not any rewards or incentives for participating in CE]. But I think if you want to do it for the community you do it, you don't really do it to get something out" (N1).

Respondents from four disciplines (Nursing, Occupational therapy, Pharmacy and Physiotherapy) expressed that $\mathrm{CE}$ is embedded as a part of the academic requirements towards obtaining their degree or "getting marks" (OT3), which could be seen as the primary objective.

"I do ...see the need to give back to the community, but I need to ensure that I pass and graduate one day to do so effectively" (P3). 
In addition, participants also mentioned personal rewards which arise from CE such as self-satisfaction, getting public exposure, obtaining knowledge and learning about diversity through their direct interactions with the community.

\section{Faculty involvement and rewards}

Participants generally identified faculty, clinical coordinators and supervisors associated with their CE modules and activities and not others not involved in these modules and activities. Students from all the disciplines highlighted that their lecturers who coordinate $C E$ at their disciplines may have personal community-based initiatives going on within communities, such as "providing students with sandwiches on a Friday at their own expense" (N1) and being "involved with the taxi committee" (D6). However, all five disciplines indicated that these "stories" are not shared with students openly and the only form of exposure all disciplines have of these lecturers' participation is seen in their research projects, publications or presentations. Pharmacy and Nursing participants mentioned that they do not know of staff members who participate in CE outside of their discipline-based programs.

Participants could give isolated examples of these lecturers advocating for $\mathrm{CE}$, which was generally appreciated by students and fostered a connection between some students and faculty. The Pharmacy participants felt that staff did not advocate enough for CE in the classroom, which would interest students greatly. Nursing participants mentioned that lecturers shared their own experiences during lectures. Occupational therapy and Dentistry participants stated that CE was advocated by lecturers during their discussions with the class. The Occupational therapy participants mentioned further that discussions were held in particular "after the community block about the experiences and lessons they acquired" (OT3).

Occupational therapy, Pharmacy and Nursing participants explained that the coordinating lecturers were also the ones that maintained the relationship between the communities as well as encourage the ethics and principles behind CE practice. Nursing participants further expressed that in order for CE to be implemented throughout the curriculum it would be beneficial if lecturers could receive support from other colleagues. Dentistry participants believed that the implementation of CE was done too late in their curriculum, while the Nursing participants also felt CE activities should start in fist year. Physiotherapy participants explained how they have seen and experienced the integrative work of academic staff in implementing their $\mathrm{CE}$ activities-ensuring that all the students receive equal exposure to learning opportunities with the community.

"...when a group had missed hydrotherapy, all the staff worked together to allow the students to have that opportunity" (PT4).

All participants indicated that no CE coordinating lecturers were given rewards and incentives for performing CE initiatives, as their intention was to provide valuable work as "acts of kindness" out of their "passion" for CE. However, Dentistry respondents mentioned that through research publications, CE is 
recognised within the discipline and profession. Occupational therapy participants mentioned that supervisors do "get paid extra" for the additional work they perform at facilities. Pharmacy participants felt that lecturers should be recognised and rewarded for the valuable work they do; while Physiotherapy participants believed that it is "in the best interest of the students" to not have any rewards or incentives for CE. Overall, there seems to be varied interpretation about how rewards were offered to lecturers.

\section{Community participation and partnerships}

All participants could describe some form of collaborative partnership that was in place for them to access their community placements. Respondents from four disciplines (Dentistry, Nursing, Occupational therapy and Pharmacy) referred to the community-university partnerships in terms of the learning sites which was spread amongst underserved communities in the Cape Town Metropole (including one semirural site), while Physiotherapy participants seemed unsure of the partnerships that were made between their discipline and the communities, but have always felt well received. The Dentistry, Occupational therapy and Physiotherapy participants described the inclusion of the communities in their training and education, and such community-university partnerships ensured the sustainability of their respective discipline-based projects.

Dentistry, Occupational therapy and Physiotherapy participants stated that students built relationships with the communities to whom they have been assigned. Occupational therapy participants further expressed that when students entered these communities, there were already "key role-players" (OT3) who welcomed them in as a "co-steering group" (OT1) who facilitated the projects, ideas and student work. Physiotherapy participants elaborated on students being involved in various campaigns held in the community they worked with and that the Physiotherapy department advertised for student assistance during sports events.

The CE approach for engagement activities was mostly based on community needs, with only Occupational therapy participants identifying with an assets-based approach.

"if you are not basing it [the project] on the [community] needs, what are you really doing?..."The only way to their [the community's] involvement if you look at their needs" (PT4).

Pharmacy participants mentioned that their involvement via their Service Learning in Pharmacy (SLiP) program across many health facilities in Cape Town does take the communities' needs into account before their visits. This is usually done in the form of meetings prior to the commencement of the SLiP blocks.

Occupational therapy participants expressed that their approach when partnering with the community was an "assets-based approach" (OT1) which allowed them as a team of stakeholders to come up with sustainable solutions for the problems they collectively identify with the community. Their practice was primarily based on an ethic of "release versus relief where it is important to release the community with 
their own strengths from their challenges rather than coming in with a short-term relief, which isn't empowering for the community and can create dependency" (OT4). Therefore, the community was always included from beginning to end with regards to the $\mathrm{CE}$ activities which students undertake on site.

Occupational therapy participants noticed that if both needs and assets-based approaches were used within the same communities by different health disciplines, it caused problems for them because "expectations are created" (OT1) from the funding that was provided by other groups rather than them using the strengths used in their approach. Therefore Occupational therapy participants attested that the approach to community engagement should be congruent across health disciplines to avoid such hurdles.

Participants noted that communication and feedback between the discipline and community were important for ensuring good outcomes. Pharmacy and Physiotherapy participants stated that there was orientation and training of community members, whilst the participants from the other three disciplines indicated they do not have any form of collaborative preparation. Nursing participants mentioned that there is only a booklet that is given to students for their referral. However, they were aware of the coordinating lecturers going to their sites or facilities before the students' activities commence, but were uncertain of any specific inclusion that occurred between the community and lecturers.

Participants expressed concerns about the apparent lack of continuity of projects they initiate in communities and questioned the sustainability of the projects and resultant social change. They also mentioned that some communities seemed fatigued from hosting students on an on-going basis. Participants also noted that the current siloed approach taken with CE at university reduced the impact projects have on communities. Pharmacy participants recognized that there were a lot of "missed opportunities" (P2) in their discipline with respect to public health campaigns when it came to social and health related issues, for example HIV-testing. Nursing participants mentioned that surveys were given out to the community as a requirement of their final assignment. Since no feedback was returned to the community, they felt such an imbalanced engagement benefits neither their discipline nor the community.

The silo approach was further reflected when none of the participants could articulate their awareness of the university's goals for CE. Occupational therapy participants however also felt they lacked an "understanding of the student community within UWC" (OT3) itself and health- related discussions taking place outside of their discipline. They also felt that the university needs to do more to be involved in advocating for "especially nearby communities who are need of support, like Kasselsvlei is just up the road and yet as a university, we don't do enough. Or speak enough" (OT1).

\section{Institutional support for CE}

The monitoring, coordination and evaluation of community engagement activities that students described was executed at the discipline level and primarily aimed at assessment of the engagement activity. Pharmacy and Nursing participants were unsure of a specific process for monitoring of their CE 
activities. However, Pharmacy students acknowledged that their lecturers may have a means of "recording statistics somewhere" (P4). Nursing participants had reported that the rigour of the assessment of each CE activity depended on the presence and quality of the supervision, which varied between activities, since they often "lack direction and supervision when sent to community sites" (N2). On the other hand, Occupational therapy and Physiotherapy participants expressed that student activities were monitored and communicated between the relevant lecturers and supervisors, which is transparent to students. With Occupational therapy, participants described a "hand-over process takes place" (OT2), where community partners and spokespersons also get involved in approving the outcomes of the projects that students will then convey to forth-coming groups to the site. In Physiotherapy, the participants indicated that supervisors perform International Clinical Frameworks for their examinations, which serves as a monitoring process during their engagement with the community at facilities.

"We have a clinical coordinator that we can refer to if we do experience any problems when we are on block. Then if there are any external problems, then, one would go to the lecturer introduced us to the site" (PT4).

All participants had claimed that they had no knowledge of a central coordinating entity for community engagement at UWC; and if they referred to a central system, they meant the IPE unit that is located on campus. Despite this, participants could articulate a clear need for such an entity at the University of the Western Cape and stated that a central CE system would be beneficial for the students. Pharmacy participants attested that it would create CE awareness, while Nursing and Occupational Therapy participants felt that it would encourage the much needed collaboration between the health disciplines, which does not operate optimally among the health disciplines. In addition to the collaboration, Occupational therapy respondents mentioned that such a central body could minimize communication barriers between the health disciplines which hindered the collaboration that would be beneficial to students. Physiotherapy participants stated that the central body would be able to provide additional CE activities outside the curriculum.

"Yes there should be [a central unit for CE]. Because we go into a community as OTs, but communities don't just need OTs. If we have a central body within the university that will link everyone together and give a more holistic approach into the community instead of putting band aids everywhere. As a team we could make more of a difference" (OT2).

Respondents from four disciplines (Dentistry, Nursing, Pharmacy, Physiotherapy) believed that funding for CE was insufficient. Nursing, Physiotherapy and Dentistry participants believed that funding for CE seemed insufficient as was evident from the many financial cutbacks in various CE activities or site visits. Nursing participants stated that they often times have to raise their own funds for various CE activities in very short time frames. Occupational therapy participants believed that the funding within their discipline towards CE is sufficient, as it is conducive to the assets-based approach to which they accustomed.

"Solving community based issues with money from the discipline is not a good solution. Instead projects that generate the needs for the community by the community end up being more sustainable with long- 
term benefits" (OT1).

However, the Occupational therapy participants felt that from a university perspective additional funding is necessary for the university to invest more effort in strengthening campus-based teaching and learning in $\mathrm{CE}$, rather than offering the funds to communities as a gesture of goodwill.

All participants were not aware of public discussion about CE at the university level, in part, because either they did not either read or recall the university's emails, yet they had suggested that the university's CE promotion or advertising should be enhanced to advance CE across all faculties.

In terms of CE goals for each discipline, all participants mentioned that exposure to real issues was a goal for the students, as well as becoming community conscious. The Pharmacy participants mentioned that CE activities "make students aware of challenges that the communities face" (P3); Nursing participants recognised their profession having a health promotion role within the community in "promoting prevention rather than cure" (N2); and Physiotherapy participants believed it essential "to be community focussed or community based" (PT5). The depth of engagement across the disciplines seemed to vary.

Suggestions to improve CE broadly covered: the allocation of more time in the academic time table towards CE activities to ensure sustainability and social change, the coordination of CE projects across disciplines to maximise impact, the inclusion of the student community on campus as part of CE activities, and the measurement of the impact on the community. Pharmacy participants suggested that students spend more time doing practical work to allow for more interaction with patients and to increase student involvement with communities on medication and health related discussions. Occupational therapy participants emphasized that communities may also "feel like they are being recycled" (OT5) due to the numerous groups of students entering their sites, resulting in community members to "switch- off to an extent" (OT5) and become "desensitized or passive to a degree from all the projects" (OT4) that were implemented. Hence, Occupational therapy participants also felt that students need to spend more time in the community to make a more beneficial impact through a multidisciplinary approach.

"Even if looking at the Kasselsvlei community we worked with in our second year. They then allowed us to do our exams during the Fees Must Fall protest because we have formed that relationship with them. They opened their doors to us to do our exams there. That's building relationships" (OT3).

\section{Second level analysis}

Themes that emerged continuously regardless of the section of the interview during the first level of analysis included; siloism in the university, interprofessional education and monitoring and evaluation for impact of CE. Siloism was most evident in the unawareness of students for the university policies, such as the students being unaware of the university's vision and mission for CE, the central office for CE as well as the absence of public discussion of CE. In addition, siloism was implicit from participant 
responses as it related to the focus of curriculum. The primary drive for student involvement in CE activities was obtaining the marks that were required for them to graduate, because CE was embedded in their curriculum. As a consequence the synonyms students gave for CE was discipline specific. Indeed, volunteerism was a relatively foreign phenomenon for students, which was firstly extra-curricular and perceived as a personal preference. This split between professional (embodied by the discipline/curriculum) and personal was in a way reinforced by the way the students perceived the faculty members involved in $\mathrm{CE}$, which was described as discipline specific and a personal passion of these lecturers. The participants could subsequently also not identify or articulate a reward for this.

Interprofessional interactions was the second most prominent theme which surfaced most explicitly in the participants responses to questions relating to the university. Indeed most groups thought that the IPE was the central community engagement unit. In addition to the discipline specific service learning, their only other reference for CE was the activities that they completed through the IPE unit. IPE also surfaced as one of the factors that could affect impact of $C E$, since they felt that could improve the continuity of community-based activities. Participants recommended that interprofessional coordination of projects could improve the outcomes of community activities since "...Communities don't just need OTs" (OT2). Another suggestion from the respondents was that students from other disciplines on campus should be involved in CE activities.

The last cross cutting theme that was more subdued in the responses was the desire for students to see impact or change in the communities. Students became very disheartened when they went to communities did their project, gave feedback, but nothing seemed to change as evident from " .. so many students are recycling the places" (OT 5). Students noted that the continuity of the CE project was important, and sustainability was cornerstone.

\section{Discussion}

The study provided insight into health science students awareness on critical factors shaping the community engagement activities at the University of the Western Cape. The discussion focuses on key aspects of community engagement pertaining to the: definition, presence of central a co-ordinating unit on campus, partnerships, the tensions arising between needs- and assets-based approaches and between students personal and professional identities.

Although all disciplines defined community engagement as their interaction with people from underserved communities, the detailed definition that each discipline provided for community engagement translated into the method that they used in order to deliver a service to the community [30]. Disciplinary differences and students tasks were linked to differences in how academics tend to define service learning as has been noted in previous research [7]. Indeed, in our research findings, the power of the discipline seemed to outweigh any type of institutionalisation of community engagement, with some participants describing outright how isolated their discipline was from the university's main campus. 
Since community engagement activities are embedded in the formal discipline-based curriculum, cocurricular activities such as volunteerism seemed marginal, in contrast to student experiences in developed countries, where volunteering seems common practice in the health sciences [31]. In South Africa co-curricular activities are generally not regarded as a priority in higher education institutions, as the primary focus for graduates is to secure employment especially in the health sector, where the human resource shortage is a growing concern [32]. Therefore in higher education, linking community engagement with the practice environment (market) would develop student competencies that would enhance their employability as future health care professionals.

Students in this study were not aware of the institutional mission and vision as it related to community engagement neither was they aware of the central community engagement unit. While the Community Engagement Unit does exist at UWC its active involvement in the health sciences is minimal. Students recommendations from this study agreed with literature that a centralized body within universities to regulate community engagement activities directly with the community will effectively streamline activities so that there is continuity, sustainability and impact that can be monitored, ultimately reducing the assortment of terms that have been personalized by individual health disciplines across South African universities for community engagement $[6,7]$. A centralized body would liaise with health facility staff, communities and students to jointly identify and address priority concerns to achieve meaningful health outcomes [22].

Instead of making reference to the university's Community Engagement Unit, participants recalled another unit, the Interprofessional Education (IPE) unit, where they had learnt about each other's disciplines during their formative years. However, interprofessional development across the university's health disciplines is either slow or not possible as disciplines generally work "in a silo". The lack of inter-professional learning opportunities is likely to lead to inadequate competence as graduates build poor relationships which affect their immersion into communities [33].

One barrier to implementing interdisciplinary learning is a 'block-session' or a specified number of weeks in a term that disciplines assign leading to the lack of continuity for activities within the community. Pharmacy adopts a CE approach which is fragmented, due mainly to a prescribed pharmacy curriculum which is very theory based. From the community's perspective, the 'block-sessions' in which students are required to hastily complete their assigned activities, result in students becoming the primary beneficiaries from the engagement rather than the community partners [7]. Indeed, the skills that are acquired from community engagement activities are directly related to real-world issues and upon completion of such activities, students are expected to make a valuable contribution to society through the enhancement of social accountability amongst citizens [4] promoting alignment towards the National Development Plan (2012), whereby "active citizenry and social activism is necessary for democracy and development to flourish" [34].

In this study participant awareness of university-community partnerships revealed varied responses. Nursing participants expressed a lack of partnership with the community, which left them with a sense of 
ambiguity when it came to their overall understanding of community engagement. In contrast, Occupational therapy participants explained that during handover of projects a community spokesperson approved the monitoring and evaluation of their course outcomes. Physiotherapy participants described that they are well-integrated within the communities. Important factors that might affect studentcommunity relationships include both the degree of reciprocity of the university-community partnership [11], as well as the pre-existing relationship between the community and healthcare professionals.

The discipline-based focus of community engagement activities seemed to divide the participants' professional and personal identities. Participants tended to associate community engagement activities as a personal passion, which they had identified arose from both students and academic staff because of the lack of institutional rewards for their effort and noted in the literature [7]. However, the students' personal passion may be perceived as a having 'saviour complex', where humanitarian acts are portrayed towards poor communities in developing countries [35]. In the needs-based approach, also identified as a deficit model, manifests unequal 'power' relationships [36] with students lacking the ethical and critical self-reflection that is required to engage on the complex contextual issues facing vulnerable communities [35]. Community engagement programs promoting student-led dialogue framed on critical consciousness and ethical engagement [35] would develop the advocacy skills required for community-based health systems strengthening.

In this study, the approach that the disciplines had used to implement to community engagement, namely needs- or assets- based, created tension between different groups of student working in the same communities. In contrast to the four health disciplines who seemed to employ a needs-based approach, the Occupational therapy participants felt that an assets-based approach using Paulo Friere's 'critical pedagogy' framework, enabled communities to become self-reliant, taking ownership of interventions thereby promoting sustainability [37]. The tension which emerged at the student level from the different approaches to community engagement at the same institution, reiterates the gap in true institutionalisation of community engagement at [this university]. Similarly, Mouton and Wildschut [7] noted the challenges of institutionalisation, which remains an elusive and delicate balance between mainstreaming which is a top-down approach and providing enough support at grass roots level for implementation. At the bottom of the hierarchy, students are required to meet the learning objectives of experiential learning programs (practise) and their campus-based theoretical component (theory). The students real world socialised learning experiences (personal) which is required to meet their academic (professional) requirements, is determined primarily by the weighting that disciplines ultimately assign to the course, which (in most cases) strongly favours the theoretical component. As such, restructuring of the discipline-based (siloed) curriculum is essential across the health science disciplines as faculty are required to embed interprofessional (team-based) learning to strengthen the health system in anticipation of the National Health Insurance [14].

Health disciplines are required to comply with their regulatory bodies, which impose restrictions on professional practice when engaging in the community. Regulatory restrictions could result in low selfinvestment for student immersion into a community, and may indirectly promote student apathy, 
contrasting with the work of their counterparts, the qualified health professionals who practise in public sector health care facilities located in underserved communities. Since students value their professional development with attaining marks, such a notion overrides their personal aspirations in community engagement activities. Therefore, equitable weighting is imperative between community engagement and the theoretical component of the undergraduate health science curricula to achieve the competencies for South African graduates to be 'fit for purpose' [1].

Despite the benefits for students who participate in community engagement activities participants in this study were not convinced about the potential of their engagements in providing sustainable solutions in communities that effect meaningful social change. Similar findings from literature attribute this scepticism of students to that fact that the time spent in communities by students during such engagements is just not enough [7]. However, while longer exposure to communities may increase community engagement skills, a balance needs to be established by universities so that communities do not become exhausted or saturated with prolonged periods of student involvement.

Participants described the coordination, monitoring, and evaluation of community engagement activities at the discipline level, which therefore focused primarily on assessing students on their learning outcomes. Such a one-sided assessment, illustrates a gap in community engagement programme planning, as assessing the overall outcome in the larger community (recipients), determines programme effectiveness [2].

One theoretical framework which could be considered for the health science disciplines is Boyers' scholarship of engagement, which consists of 4 models: the scholarship of discovery which relates to faculty undertaking research to produce new knowledge; the scholarship of integration refers to faculty having the ability to make connections across different disciplines to create interdisciplinary learning pathways; the scholarship of application refers to faculty identifying ways in which knowledge can be applied to solve real world problems (practice), so that learning (theory) becomes relevant and authentic to society; and the scholarship of teaching where faculty serves as a bridge to create a learning space to transmit knowledge to the student [12].

The main limitations of the study are attributed to time constraints for each the focus group discussion. A minimum of 35 minutes to a maximum of an hour was allocated to conduct the interviews due to a time limitation imposed by the study participants to enable them to fulfil their academic schedule requirements. This resulted in some groups being unable to provide in-depth answers. During the discussions, some students were more willing and engaging to discuss the points than their counterparts. Focus group discussions from faculty would have assisted in validating the findings from this study. With the limited findings in this study, the results cannot be generalised to other health science disciplines.

\section{Conclusion}


The research set out to explore student awareness of critical factors which shape community engagement in the health science disciplines. Students' awareness was primarily limited to their discipline-based community engagement activities. A framework for CE across healthcare disciplines is needed to standardise teaching and learning approaches which is suited to sustainably address local health needs and improved practices.

Boyer's 'scholarship of engagement' underpins discovery, integration, application and teaching would provide a conceptual framework [12].Knowledge generation, interprofessional collaboration, critical analysis skills, ethical principles and moral values are essential components. In a developing country, community engagement should be regarded as part of the core undergraduate curriculum with explicit and defined outcomes; however, it is not recognized as such and not given much prominence in higher education in South Africa.

It is recommended that health science students engaging in CE programs should be trained as advocates for social transformation that moves beyond curricular boundaries. A centralized body to manage CE activities could therefore serve as a conduit to promote health advocacy programs. Further quantitative research such as electronic surveys should be the next step to obtain more robust findings on the impact of community engagement programs at both community and institutional levels.

\section{Abbreviation}

CE: Community engagement; FGD: focus group discussion; UWC: University of the Western Cape, South Africa; WHO: World Health Organisation.

\section{Declarations}

\section{Acknowledgements}

The authors are grateful to the final-year health science students who participated in the research. The student researchers who conducted the focus group discussions and first round of data analysis; D. Boswell, S. Conradie, B. Keshave, T. Khan, N. Mngadi and L. Tebeile were extremely helpful.

\section{Authors' contributions}

All authors are involved in community engagement programs at the Faculties of Natural Science (AB, $\mathrm{MVH}$ ) and Community and Health Sciences $(\mathrm{HJ})$ at UWC. The design of the study was initiated by the third author $(\mathrm{HJ})$; the data collection process was conducted by the first $(\mathrm{AB})$ and second $(\mathrm{MVH})$ authors. The first draft was written by the first ( $A B)$ and second (MVH) authors, and subsequent drafts were checked by all three authors ( $A B, M V H ~ H J)$, until the final version for submission was agreed upon. The last author $(\mathrm{HJ})$ reviewed the qualitative data until finalising the manuscript. All authors provided consent 
to publish this study to the BMC Medical Education journal. All authors read and approved the final manuscript.

\section{Funding}

The National Research Foundation provided the funding for this research: grant numbers: CEC 14061870029 and CEC160425163068.

\section{Availability of data and materials}

Data of this qualitative study was obtained from the focus group discussions conducted by the six student researchers with participants from the health disciplines at the University of the Western Cape. The focus group discussions were conducted in English. Transcriptions and the first coding processes were checked independently and by all the authors. The data could be retrieved on reasonable request.

\section{Ethics approval and consent to participate}

Ethics approval for the study was obtained from the Humanities and Social Sciences Research Ethics Committee (HS/17/8/27). Approval from the registrar was granted to conduct the study at the University for the period 28 March 2018 to 22 March 2019. Principles of informed consent, respect for the participants 'rights in terms of privacy, autonomy, beneficence and confidentiality were upheld during the research. Anonymity of the participants was maintained, as researchers assigned unique codes to each participant's responses. A participant information sheet explaining the study objectives, question guide was provided to all participants before the FGD. Informed consent was obtained and participants were informed of their right to withdraw at any stage of the research. Participants also had to sign the binding FGD agreement prior to the discussion to ensure confidentiality. The data collected on the audiotapes were stored on a password protected computer system. No risks were identified during data collection.

\section{Consent for publication}

Not applicable

\section{Competing interests}

The authors declare that they have no competing interests.

\section{Author details}


${ }^{1}$ School of Pharmacy, Faculty of Natural Science, University of the Western Cape, Bellville, Cape Town, South Africa.

${ }^{2}$ Faculty of Community and Health Sciences, University of the Western Cape, Bellville, Cape Town, South Africa.

\section{References}

1. Aretz H T. Some thoughts about creating healthcare professionals that match what societies need. Med Teach. 2011; 33(8): 608-613.

2. Boelen C, Heck JE.Defining and measuring the social accountability of medical schools. No. WHO/HRH/95.7. Unpublished. Geneva: World Health Organization. 1995.

3. Frenk J, Chen L, Bhutta ZA, et al. Health professionals for a new century: Transforming education to strengthen health systems in an independent world. Lancet, 2010; 376 (9756):19231958.DOI:10.1016/S140-6736(10)61854-5. Accessed 30 June 2017.

4. Boelen C, Woollard B. Social accountability and accreditation: a new frontier for educational institutions. Med Educ. 2009; 43(9): 887-894.

5. 5. Department of Education. Education White Paper 3. A programme for higher education transformation. Government Gazette No: 18207.Pretoria: Government Printers.1997.

6. Bender G. Exploring conceptual models for community engagement at higher education institutions in South Africa: conversation. Perspectives in Education 2008; 26(1): 81-95.

7. Mouton J, Wildschut L. Service learning in South Africa: lessons learnt through systematic evaluation. Acta Academica 2005;(3):116-150.

8. Furco A. Service-learning: A balanced approach to experiential education. Washington DC: Corporation for National Service. 1996; 2-6. http://www.wou.edu/ girodm/670/service_learning.pdf. Accessed 14 May 2017

9. Seifer SD. From placement site to partnership: the promise of service-learning. Journal of Nursing Education 2002; 41(10): 431-432.

10. Larrivee B. Transforming teaching practice: Becoming the critically reflective teacher. Reflective practice 2000; 1(3): 293-307.

11. 11.Bhagwan R. Towards a conceptual understanding of community engagement in higher education in South Africa. Perspectives in Education 2017; 35(1): 171-185.

12. Boyer E. Scholarship Reconsidered: The Carnegie Foundation for the Advancement of Teaching. JosseyBass. San Francisco Ca. 1990

13. Council on Higher Education (South Africa). Higher Education Quality Committee. A good practice guide and self-evaluation instruments for managing the quality of service-learning. Council on Higher Education. 2006 
14. Academy of Science of South Africa. Reconceptualising health professions education in South Africa. Consensus study report. March 2018. Pretoria. http://dx.doi,org/10.17159/assaf.2018/0021.

15. National Department of Health. Status of the NHI pilot districts. Progress report. 2016.

16. Heleta S. Decolonisation of higher education: dismantling epistemic violence and Eurocentrism in South Africa. Transformation in Higher Education 2016; 1(1): 1-8.

17. Jacobs S. Student protests and post-apartheid South Africa's negative moment. Africa is a Country. May 18, 2016. https://www.africasacountry.com/2016/05/postapartheid-south-africas-negativemoment Accessed 6 January 2019

18. Kaya $\mathrm{OH}$, Seleti YN. African indigenous knowledge systems and relevance of higher education in South Africa. International Education Journal: Comparative Perspectives 2014; 12 (1).

19. Smith-Tolken AR. Community engagement at a higher education institution-exploring a theoretical grounding for scholarly-based service-related process. [PhD dissertation] University of Stellenbosch. Stellenbosch. 2010.

20. Mclnerney P, Green-Thompson LP, Manning DM. Experiences of graduating students from a medical programme five years after curriculum transformation: a descriptive study. African Journal of Health Professions Education. 2013;5:34-36. DOI:10.7196/AJHPE.210

21. Furco A. Self-assessment rubric for the institutionalization of service-learning in higher education. Service learning Research and Development Center. University of California, Berkeley.1999.

22. Lazarus J, Erasmus M, Hendricks D, Nduna J, Slamat J. Embedding community engagement in South African higher education. Education, citizenship and social justice. 2008; 3(1):57-83.

23. Julie H, Smith-Tolken A, Dippenaar H. Institutionalisation of Engaged Teaching and Learning in South African Higher Education. Humanities and social sciences research ethics committee. Ethics clearance \# HS /17/8/27. Faculty of Community Health Sciences, University of the Western Cape. 2018

24. Polit DF, Beck CT. Essentials of nursing research: Appraising Evidence for Nursing Practice (seventh). Philadelphia: Wolter Kluwer Health. 2010

25. Neuman, WL, Kreuger L. Social work research methods: Qualitative and quantitative approaches. Allyn and Bacon. 2003.

26. University of the Western Cape website (https://www.uwc.ac.za/). Accessed 2 May 2019

27. University of the Western Cape. Annual Report. Bellville. South Africa. 2017.

28. University of the Western Cape. Institutional Operation Plan 2016-2020. University of the Western Cape. Bellville. Cape Town. 2016.

29. Samuels GJ, Cooper JA. Leonard P. Community Engagement Database Report. Database. Cape Town. 2017. Accessed 10 June 2019.

30. Council on Higher Education, South Africa. Community Engagement in South African Higher Education. Kagisano No. 6. Council on Higher Education, South Africa Pretoria, South Africa. Jacana 
Media (Pty) Ltd. 2010. https://digitalcommons.unomaha.edu/cgi/viewcontent.cgi? referer = https://www.google.com/\&httpsredir = 1\&article = 1105\&context = slceslgen. Accessed 04-2018.

31. Sheu LC, Zheng P, Coelho AD, et al. Learning through service: student perceptions on volunteering at interprofessional hepatitis B student-run clinics. Journal of Cancer Education 2011; 26:228-233. DOI 10.1007/s13187-010-0142-6.

32. Department of Health. South Africa. Human Resources for Health. South Africa 2030. Draft HR strategy for the Health Sector: 2012/13-2016/17. Consultation document v5. 2011.

33. El-Awaisi A, Anderson E, Barr H, et al. Important steps for introducing interprofessional education into health professional education. Journal of Taibah University Medical Sciences. 2016; 11(6): 546-551.

34. National Planning Commission. National Development Plan 2030. Our future-make it work. The Presidency. Republic of South Africa. 2012

35. Dharamsi S, Nashon S, Wong A, Bain P, et al. Saving Africa: a critical study of advocacy and outreach initiatives by university students. Journal of Global Citizenship \& Equity Education 2013; 3(1): 5367.

36. Morgan A, Ziglio E. Revitalising the evidence base for public health: an assets model. Promotion \& Education. 2007;14 (2):17-22.

37. Freire P. A critical encounter. USA and Canada: Routledge. 1993.

\section{Table 1}

Table 1: A priori themes and subthemes 


\begin{tabular}{|c|c|}
\hline A priori themes & Sub-themes \\
\hline $\begin{array}{l}\text { University's } \\
\text { philosophy and } \\
\text { mission of CE }\end{array}$ & $\begin{array}{l}\text { CE defined as interaction with people in underserved contexts. } \\
\text { Synonyms for CE where discipline and task specific. } \\
\text { Most used terminology was service learning (in contrast to work integrated learning) } \\
\text { embedded into the formal curriculum. } \\
\text { Volunteerism associated with co-curricular activities and its prominence was negated when } \\
\text { compared to the importance of 'marks' and graduating. } \\
\text { Unaware of the university's vision and mission. }\end{array}$ \\
\hline $\begin{array}{l}\text { Student } \\
\text { involvement }\end{array}$ & $\begin{array}{l}\text { Experiential learning and some on-campus training prepares students for CE. } \\
\text { Interprofessional teaching and learning unit activities on campus. } \\
\text { All students were involved in CE as it is part of the curriculum. } \\
\text { Rewards were a mix of self-satisfaction, obtaining marks and graduation. }\end{array}$ \\
\hline $\begin{array}{l}\text { Faculty } \\
\text { involvement }\end{array}$ & $\begin{array}{l}\text { Involvement was limited to lecturers, clinical coordinators and supervisors involved in } \\
\text { service learning activities. } \\
\text { Little advocacy for CE by lecturers } \\
\text { Rewards were associated with personal passions and interests. }\end{array}$ \\
\hline $\begin{array}{l}\text { Community } \\
\text { participation } \\
\text { and } \\
\text { partnerships }\end{array}$ & $\begin{array}{l}\text { Collaborative partnerships are in place. } \\
\text { CE approach to participation: needs versus assets-based } \\
\text { Factors important for impact / social change: } \\
\quad \text { Communication and feedback } \\
\text { Missed opportunities and reduced impact due to working in silos. }\end{array}$ \\
\hline $\begin{array}{l}\text { Institutional } \\
\text { support for CE }\end{array}$ & $\begin{array}{l}\text { Monitoring, coordination and evaluation of CE activities was at the discipline level in terms } \\
\text { of assessment. } \\
\text { No knowledge of a central coordinating entity for CE, students could articulate a clear need } \\
\text { for this at UWC. } \\
\text { Most participants thought funding for CE was insufficient. } \\
\text { Unsure of public discussion, do not read or recall UWC emails. } \\
\text { Recommendations included more consistency and sustainability of projects, which required } \\
\text { interprofessional coordination and more time as well as measuring the impact, and } \\
\text { including the on campus community in CE activities. }\end{array}$ \\
\hline
\end{tabular}

